\title{
Manifestaciones del sincretismo religioso y las prácticas mágicas en la prostitución

\author{
Manifestations of religious syncretism and magical \\ practices in prostitution
}

\author{
José LÓPEZ RIOPEDRE \\ Profesor-Tutor de Sociología y Antropología Social UNED \\ Escuela de Ciencias Policiales de la Universidad de Vigo. \\ jose.lopez@lugo.uned.es (ESPAÑA)
}

Recibido: 25.052011

Aceptado: 13.05 .2012

\section{RESUMEN}

Prácticas mágico-religiosas y prostitución son dos fenómenos con interesantes puntos de conexión. En este artículo se aborda una aproximación a esta realidad de la mano de los cultos sincréticos que procedentes de países latinoamericanos como Brasil se ha ido asentado en España a través de los flujos migratorios, desarrollando aquí su propia evolución. El marco de análisis seleccionado es la industria del sexo, constatando así la práctica de rituales específicos como la pomba gira donde la invocación de las entidades espirituales se pone al servicio de la prostitución.

\section{PALABRAS CLAVE}

Sincretismo, sacralización, prácticas mágicas, flujos migratorios, prostitución, industria del sexo, pomba gira.

\begin{abstract}
Magic-religious practices and prostitution are two phenomena with interesting linking points. This article discusses an approach to this reality through syncretic cults which, via Latin American countries as Brazil, have been established in Spain through migration, developing their own evolution here. The
\end{abstract}


analytical framework chosen is sex industry, thus stating the practice of specific rituals such as pomba gira, where the invocation of spiritual beings is at the service of prostitution.

\section{KEY WORDS}

Syncretism, sacralization, magical practices, migratory flows, prostitution, sex industry, pomba gira.

\section{INTRODUCCIÓN}

Tradicionalmente los estudios e investigaciones acerca de la prostitución vienen a ignorar la cuestión religiosa como si se tratase de dos esferas de la realidad social sin punto alguno de conexión. Lo cierto, es que actualmente el discurso de la trata y de la explotación sexual ha acaparado tanto protagonismo en el abordaje de la prostitución no sólo en el debate público sino también en el mundo académico, que cualquier otra línea de indagación posible deviene secundaria en la práctica.

Debo confesar que en un primer momento tampoco yo he sido completamente inmune a esta tendencia de obviar el fenómeno religioso como cuestión de interés para el ámbito de la prostitución. No obstante, fueron los hallazgos durante el período de trabajo de campo (2002/07) y sobre todo, la insistencia de mi entonces director de tesis, José Antonio Nieto, los que me brindaron una perspectiva diferente y avivaron mi interés en este sentido. Pronto comprendí que la descripción de prácticas religiosas y episodios sobrenaturales en el discurso de los sujetos no era algo casual, sino que obedecía a hechos y situaciones sociales concretas que bien merecen nuestra atención.

En este artículo se presentan datos que sirven para incorporar la cuestión religiosa al estudio de la prostitución. Más allá de admitir la relevancia de esta realidad en el discurso de los sujetos y de constatar el advenimiento de las prácticas sincréticas de la mano de los flujos migratorios, lo que evidencia por otra parte el origen de un marco socio-cultural más amplio donde el sincretismo es compartido por migrantes al margen de la prostitución ${ }^{1}$, subyace un deseo de advertir dos hechos fundamentales: $1^{\circ}$ ) que existe una práctica mágico-religiosa aplicada al singular contexto del trabajo sexual y de la industria del sexo; y $2^{\circ}$ )

1 El presente estudio se centra en las prácticas sincréticas manifestadas en un contexto de prostitución, siendo la muestra principal mujeres migrantes de Latinoamérica que desempeñan trabajo sexual en España. Obviamente, esto no significa que se establezcan inferencias entre el sincretismo y la prostitución, pues las prácticas sincréticas se hallan determinadas por el particular universo socio-cultural independientemente de cualquier sector ocupacional, sino que lo que se persigue más bien es destacar ahora el dinamismo y la introducción de estas mismas prácticas en un sector concreto.

EMPIRIA. Revista de Metodología de Ciencias Sociales. N. ' 24, junio-diciembre, 2012, pp. 93-116. ISSN: $1139-5737$ 
que como consecuencia de la preponderancia del discurso de la trata y de la explotación sexual este tipo de prácticas resultan frecuentemente contaminadas de una visión prejuiciada a la vez que, por otro lado y paradójicamente, se intensifica la sacralización de la sexualidad en Occidente. Lo que se pretende, en síntesis, con este trabajo es llamar la atención acerca de la existencia de un contexto singular donde la invocación de lo divino y lo sobrenatural por parte de los sujetos se dirige a la obtención de resultados específicos en y para la prostitución, mientras el «hecho discursivo global» (Foucault, 2005) se sustenta en parámetros de similar carácter sacro con el fin de legitimar su obstinada condena del comportamiento sexual «desviado».

A lo largo de la historia, el sexo ha sido considerado como un elemento de hondo carácter sagrado. «Virtud» que no ha sido eclipsada por el mero hecho de la presencia de cualquier forma de contraprestación durante el intercambio sexual. Así, durante la Antigüedad las ceremonias con manifiesto componente sexual eran corrientes en Grecia y otras regiones del Mediterráneo, como se demuestra de los testimonios acerca de las ofrendas en el templo de Afrodita y de la eclosión de una prostitución religiosa. Por otro lado, este tipo de prácticas no son del todo ajenas a nuestro mundo contemporáneo y resisten en algunos contextos socio-culturales concretos como es el caso de los hijra ${ }^{2}$ en la India o de determinados grupos sectarios ${ }^{3}$.

Sin embargo, nuestra sociedad occidental, la misma que desde el siglo XIX hace alarde de tan lograda secularización, no deja de dar muestras de cierta ambivalencia moral y religiosa en cuestiones de sexualidad. Así, a la recurrente afirmación de que el sexo continúa siendo tabú habría que añadir hoy que la creciente proscripción de ciertas conductas como la prostitución en aras de los discursos de la explotación sexual y la violencia de género tiende, una vez más, a la sacralización del sexo. Y esta perversión de los discursos representa, sin duda, un marcado retroceso en lo referente al marco de libertades individuales y derechos fundamentales ${ }^{4}$.

Recorte que deriva de un modelo de sexualidad conducente (Nieto, 2011) que, como bien señala este autor, proviene también de causas políticas. Pero, que además, ha sido alentado con renovada energía desde posicionamientos ideológicos abolicionistas y neo-conservadores ${ }^{5}$, recuperando así el carácter sagrado para la sexualidad, sobre todo para la sexualidad de la mujer convirtiendo de nuevo a ésta en receptáculo pasivo (víctima) de los bajos instintos del arquetipo del varón depredador. En otras palabras, el vigente paroxismo punitivo de la prostitución se sustenta en la neo-sacralización del sexo de la mujer.

Curiosamente, la perspectiva varía en función del observador y del hecho observado. Los rituales sincréticos son aquí vistos con recelo, y si afloran en un

2 A pesar de que a los hijra se les relaciona con el ascetismo, su afinidad con la prostitución se halla bien documentada. Véase en este sentido Nanda en Nieto ed. (2000: 261-274).

3 Sectas religiosas como los Raelianos, Niños de Dios, Ceis, etc, imprimen un importante carácter sexual a su doctrina.

4 López Riopedre, 2011.

EMPIRIA. Revista de Metodología de Ciencias Sociales. N. ' 24, junio-diciembre, 2012, pp. 95-118. ISSN: $1139-5737$ 
contexto de prostitución son rechazados de inmediato, calificándose sistemáticamente de brujería, magia negra e instrumento del delito.

La mayoría de los resultados que aquí se exponen provienen de un estudio más amplio sobre la prostitución en los pisos de contactos cuyo trabajo de campo se ha desarrollado principalmente en la ciudad española de Lugo durante los años 2002 a $2007^{6}$. A partir de este marco etnográfico y de las entrevistas realizadas se ha procedido a la construcción de 44 relatos biográficos de trabajadoras sexuales colombianas (14) y brasileñas (30), cuyos colectivos son los más representados en este sector en Galicia. Asimismo, los diferentes fragmentos émicos que refieren el sincretismo religioso y que articulan este trabajo pertenecen a ese mismo conjunto narrativo. Por último, y de forma complementaria, se recabó también información de un grupo más amplio y heterogéneo de sujetos a través de un cuestionario de 100 ítems, donde la cuestión religiosa ocupa el último apartado (con tres preguntas) de un total de once temas generales.

\section{EL SINCRETISMO ${ }^{7}$ COMO FENÓMENO RELIGIOSO}

Las trabajadoras sexuales no son personas especialmente religiosas o al menos no más que otras de igual origen étnico o cultural. Así, en el cuestionario que se confeccionó inicialmente para la muestra cuantitativa ${ }^{8}$ se recogen dos preguntas cerradas y una abierta sobre práctica religiosa, y los resultados analizados indican que la mayoría de la población estudiada se identifica con la religión cristiana católica (99\% en la muestra colombiana frente al $65 \%$ en la muestra brasileña) y que la mayor diversidad de cultos aparece en el conjunto de mujeres brasileñas. Las diferencias entre ambas muestras son, pues, significativas, aunque hay que tener en cuenta también que no existe proporcionalidad dado que el conjunto de brasileñas es bastante mayor (en una proporción similar a la muestra cualitativa $^{9}$ ) que el de colombianas. A pesar de esta circunstancia, se observa una

5 Para una crítica a la postura abolicionista y a las alianzas entre la derecha política y religiosa y las feministas radicales, véase Weitzer, 2006.

${ }^{6}$ López Riopedre, 2010.

7 Recientemente, algunos autores se muestran muy críticos con el uso generalizado de este término. Ver, por ejemplo, el artículo «Entre Oyá y santa Teresa. El controvertido asunto del sincretismo en la santería» de Jesús Fernández Cano, en Gazeta de Antropología, nº 21, 2005. En este artículo el autor lleva a cabo un interesante análisis crítico de este concepto, llamando a la vez la atención sobre aquellos fundamentos ideológicos y etnocentristas que resultan implícitos a la asignación indiscriminada de sincretismo hacia los cultos de origen africano y amerindio, mientras por otro lado, lo cierto es que todas las religiones han recibido una mayor o menor influencia de otras dado que cualquiera de ellas constituye una realidad dinámica en un proceso de constante transformación. También Parker (2000) aboga por una revisión crítica de los marcos conceptuales y metodológicos en la ciencia social de la religión, proponiendo una estrategia de des-occidentalización de la misma.

8 Muestra de 63 trabajadoras sexuales, 57 mujeres y 6 travestis.

9 Muestra de 44 relatos biográficos.

10 Sobre ambivalencia religiosa ver también el artículo arriba citado.

EMPIRIA. Revista de Metodología de Ciencias Sociales. N.o 24, junio-diciembre, 2012, pp. 93-116. ISSN: $1139-5737$ 
presencia destacada de prácticas de culto sincréticas entre las mujeres brasileñas, algunas de las cuales se identifican simultáneamente con el cristianismo ${ }^{10}$ y otras no. Este hecho guarda a su vez relación con otra circunstancia, y es la de que la mayoría de las brasileñas que dicen ser creyentes del cristianismo católico afirman también que no son practicantes, al contrario de la mayoría de las mujeres colombianas que afirman ser católicas practicantes. El origen de estas diferencias observadas tiene obviamente una base étnica y cultural.

El concepto de sincretismo fue formulado por primera vez por Herskowitz (1937) al observar «la profunda mezcla de significados religiosos africanos y formas cristianas presente en las culturas de los negros africanos trasladados al Nuevo Mundo» (Malgesini y Giménez, 2000: 388-389). Es en este sentido que se aplica aquí el término para designar a toda una amalgama de cultos y rituales que, en general, tienen su origen en las religiones animistas africanas y que llegaron al continente americano de la mano de los esclavos negros traídos a la fuerza desde África por los mercaderes de mano de obra esclava. La interpretación más común a esta fusión de elementos propios del catolicismo y de las religiones animistas africanas es la de que al imponerse la religión católica en países como Cuba o Brasil los esclavos africanos enmascararon los ritos y cultos africanos con la imaginería cristiana con el fin de poder continuar su práctica en un contexto diferente (Herskowitz, 1941; Rodrigues, 1945; Bastide, 1960). En cambio, en tiempos más recientes esta interpretación es tachada por diversos autores de excesivamente simplista, afirmando en su lugar que el sincretismo obedece más bien a un proceso de internalización de los conceptos católicos adquiridos a lo largo del tiempo (Brown, 2003; Fernández Cano, 2005) lo que le proporciona a este sistema una identidad y una orientación propias. Desde esta perspectiva, el sincretismo se concibe mejor como «un mecanismo defensivo puesto en marcha por los esclavos y sus descendientes mantenido hasta la actualidad como una costumbre que pasó a formar parte de la tradición en la ocha o santería» (Fernández Cano, 2005: 3) o bien como «un procedimiento de apropiación de elementos de cultos eruditos, desde un espacio religioso subalterno y en términos de su propia lógica y necesidades simbólicas» (Giobellina, 2005: 445). ${ }^{11}$ Para este último autor el intercambio de elementos característico del sincretismo religioso está muy relacionado con los flujos migratorios y el cambio social que se advierte en este contexto puede observarse hoy también en nuestras corrientes migratorias ${ }^{12}$, tal es el caso de la compuesta por mujeres brasileñas.

Brasil es hoy uno de los países donde la efervescencia multicultural ha dado lugar a una mayor riqueza en cuanto a creencias y manifestaciones religiosas que

11 Ver el artículo «A propósito de la jurema. Reflexiones sobre el campo religioso brasileño» de Fernando Giobellina Brumana publicado en la Revista de Antropología de la USP en 2005, v. 48, $n^{\mathbf{o}} 2$.

12 En este sentido, Jorge De Carvalho menciona la expansión de algunos de estos ritos afrobrasileros a través de los flujos migratorios, que en el caso del candomblé alcanza países como Argentina, Uruguay, Chile, Venezuela, Estados Unidos, Portugal y hasta Marruecos (2001: 125).

EMPIRIA. Revista de Metodología de Ciencias Sociales. N. ${ }^{2}$ 4, junio-diciembre, 2012, pp. 95-118. ISSN: $1139-5737$ 
no tiene parangón en otras partes del mundo ${ }^{13}$. El catolicismo comparte y compite con evangélicos y sectas protestantes de todo tipo, budismo, espiritualismo, ocultistas, animistas y diversos grupos de lo que de modo más genérico se conoce como ritos afro-brasileros ${ }^{14}$. Entre estos, destacan algunos como la umbanda, la macumba o el candomblé, corrientes del sincretismo que han despertado desde hace mucho tiempo el interés de antropólogos, sociólogos, psicólogos sociales, psicoanalistas y estudiosos del fenómeno religioso. A su vez, la práctica de algunos de estos ritos ha traspasado las fronteras y ha llegado a los países de recepción de la mano de los flujos migratorios. De hecho, existen signos evidentes de prácticas sincréticas en nuestro país tal y como comentan diversos informantes. Incluso, algunas de las protagonistas de este estudio dedican una parte significativa del contenido de los relatos biográficos a hablar de creencias y ritos religiosos y ello sin que el investigador haya pensado de antemano en la importancia del fenómeno religioso en relación con el objeto de estudio. Así, en los relatos biográficos de varias mujeres brasileñas encontramos descripciones de estos ritos afro-brasileros, pero también entre las mujeres colombianas se hallan referencias y algunas narraciones donde las protagonistas re-elaboran conjuntamente elementos sobrenaturales con determinadas prácticas mágicas y de brujería. Por otro lado, y al margen de este tipo de rituales, el fenómeno religioso cobra también relevancia en la vida de aquellos sujetos que se revelan contra restricciones de carácter fundamentalista ${ }^{15}$, como es el caso de Xuxa ${ }^{16}$ cuando rememora el culto evangélico que practicaba su familia; o en aquellos otros que, en cambio, encontraron precisamente en la religión un sistema de integración psicológica y de reafirmación de valores como le ocurre a Bia con su descubrimiento del budismo. Todo ello me ha llevado a consolidar el interés socio-antropológico por este tipo de prácticas en un contexto de prostitución.

Existe una abundante bibliografía sobre el estudio del fenómeno religioso en Latinoamérica. Entre los diversos ritos y cultos de carácter afro-brasilero desta-

13 Rodrigues Brandâo ofrece en «O Festim dos bruxos» (1987) un marco sociológico muy completo para interpretar la aflicción religiosa en Brasil. Ver también el artículo «El Misticismo de los espíritus marginales» de José Jorge de Carvalho, publicado en la Revista Colombiana de Antropología, vol. 37, 2001 (112-150) donde el autor reflexiona sobre la diversidad religiosa en la sociedad brasileña.

14 M. Eliade y Ioan Couliano fechan el surgimiento de los cultos afro-brasileños en torno a mediados del siglo XIX y a partir de elementos de origen diverso. Según estos autores este tipo de cultos presentan rasgos típicamente africanos como son la posesión por las divinidades orisas y la danza extática (Eliade y Couliano, 1997: 43).

15 Jorge De Carvalho (2001) alude a la acelerada expansión de las sectas protestantes en Brasil durante las últimas décadas, particularmente del pentecostalismo, lo que está llevando a una ruptura y transformación del universo religioso nacional caracterizado hasta entonces por un carácter abierto y sincrético y que está siendo sustituido parcialmente por doctrinas religiosas de carácter más excluyente y radical. En el mismo sentido, Milene Santos (2011).

16 Los relatos biográficos se encuentran reunidos en el vol. 2 de la tesis doctoral del autor: $I n$ migración colombiana y brasileña y prostitución femenina en la ciudad de Lugo: Historias de vida de mujeres que ejercen la prostitución en pisos de contactos. Dep. Sociología I, Facultad de Ciencias Políticas y Sociología. UNED, Madrid, 2010.

EMPIRIA. Revista de Metodología de Ciencias Sociales. N.o 24, junio-diciembre, 2012, pp. 93-116. ISSN: 1139-5737 
ca la umbanda, «complejo mágico-religioso en el que todas sus manifestaciones giran alrededor de los poderes, favores, castigos, exigencias, en fin, presencias de espíritus; en el que su centro vital está representado por la posesión por parte de estos espíritus de aquellos agentes que, por don natural y adiestramiento, actúan como instrumento de mediación entre la esfera espiritual y los hombres» (Giobellina y Evangelina, 1984: 228). En la umbanda pueden apreciarse fácilmente los diferentes factores o elementos que producen el sincretismo religioso, observándose una dinámica integración entre ritos animistas de origen africano, creencias religiosas amerindias, catolicismo y diversos elementos tomados del ocultismo y del espiritismo kardecista ${ }^{17}$. Esta influencia del espiritismo de origen europeo es muy marcada en los orígenes de los rituales de umbanda y se manifiesta tanto en las prácticas de invocación a los muertos, así como en las creencias en la reencarnación y en la adivinación. Existen además un nutrido panteón de entidades y divinidades umbandistas (Oxalá, Yemanjá, Ogum, etc) y una jerarquía «litúrgica» perfectamente organizada, comandada por los denominados «pai de santo» ${ }^{18}$ quienes lideran una gran variedad de rituales. Sobre ellos puede encontrarse también abundante material etnográfico ${ }^{19}$. En mi caso, durante el período de trabajo de campo realizado en Brasil (agosto/octubre 2000) tuve la fortuna de poder asistir como espectador al menos a una ceremonia de umban$\mathrm{da}^{20}$ gracias a la intermediación de Luciana, una de mis informantes clave quien también me presentó al pai de santo Alex, líder espiritual carismático que hablaba con igual naturalidad de los valores morales que de los bienes terrenales. Ya entonces pude observar el carácter abierto y flexible de este tipo de comunidades y me llamaba la atención el hecho de que la condición de trabajadora sexual de Luciana no suponía ningún tipo de impedimento para su total integración y ascenso social dentro del orden jerárquico de la comunidad de umbanda.

Además de la umbanda, de la información recabada en este estudio aparecen referencias de ritos de macumba y candomblé. No es sencillo establecer diferencias claras entre estos diversos cultos y rituales. De hecho, los términos macumba y umbanda se utilizan con frecuencia indistintamente, aunque al mismo tiempo el ritual quimbanda o macumba se reserva para hacer referencia a una forma más primitiva o ancestral de estas prácticas religiosas que pueden tener un carácter mágico y/o maléfico. Por su parte, el candomblé parece manifestarse

17 Se considera a Alain Kardec, fundador de la rama francesa del espiritismo contemporáneo, como uno de los ideólogos de la umbanda. Así, para Giobellina y Evangelina la umbanda surge institucionalmente como una escisión del espiritismo kardecista en las primeras décadas del siglo XX, entonces en manos de sectores de la clase media blanca (1984: 230).

18 Padre de santo. Representa la máxima autoridad dentro de la jerarquía umbandista, siendo su influencia muy importante para todos los miembros de la comunidad ya que aparte de dirigir los diversos rituales y ceremonias, hace auténticas funciones de consejero personal.

19 Bastide (1958); Giobellina y Evangelina (1984).

20 Esta ceremonia tuvo lugar la noche del 6 de octubre de 2000 en un «terreiro» en la isla de Florianópolis (Santa Catarina) y su función era a modo de acto de iniciación/presentación de cuatro nuevos miembros en la comunidad. Para una breve descripción del acto ver Riopedre (2004: 117).

EMPIRIA. Revista de Metodología de Ciencias Sociales. N. ${ }^{24}$, junio-diciembre, 2012, pp. 95-118. ISSN: $1139-5737$ 
como una forma de religiosidad africanista más pura, recuperando la vertiente más animista de este tipo de rituales. Algunos autores establecen también distinciones entre estos diferentes cultos en base a su procedencia geográfica ${ }^{21}$.

Quizás el de Cinthia sea uno de los relatos biográficos donde pueden encontrarse más elementos directamente relacionados con la religión y los ritos afro-brasileros. Su vida ha estado marcada desde el principio por el contexto ceremonial macumbero debido a que su madre, según ella relata, ejercía de mâe de santo, aunque más tarde se mudó al credo evangélico por influjo del que se convertiría luego en su esposo. De esta forma, la vida de Cinthia oscila entre un universo de creencias protestantes y otro de rituales afro-brasileros que sin duda han ejercido una notable influencia en la evolución de su personalidad, aunque ello no ha evitado que se muestre al mismo tiempo escéptica y desconfiada ante cualquier propuesta de carácter espiritual. De hecho, Cinthia manifiesta un sentido religioso profundamente pragmático e instrumental, pasando a establecer claras inferencias entre algunos acontecimientos mundanos que le afectaron a ella y a su familia y el surgimiento de la efervescencia religiosa.

"Como mi padre nunca estaba en casa, mi madre montó un centro de macumba. Ella quería volver a conquistarlo. Aquello no era una forma de vivir. Es por eso que digo que era un inferno. Recuerdo aquella oscuridad..., las velas encendidas, galinhas sem cabeça, sangre, mucha sangre en los cuencos, mucha gente en casa..., y así era todo el día y toda la noche.

Mi madre me mandaba comprar las galinhas y las velas. Yo era una niña, pero le ayudaba a hacer la macumba, participaba de todo eso aunque sin entender nada porque era тиy pequeña. Cuando había posesiones y algunas personas viraban todas tortas, y hablaban con aquellas voces extrañas y feas, yo salía corriendo. Era una cosa de dar mucho miedo. Tenía cinco años y eso duró hasta que cumplí bien los diez.

Cuando cumplí los diez años conocí a unos vecinos que eran evangélicos, y a ellos no les gustaba nada todo aquello de la macumba. Todo comenzó a cambiar. Yo iba a la iglesia evangélica a escondidas. Si mi madre se enteraba com certeza me daría una paliza. A ella no le gustaban los evangélicos, y xingaba a los creyentes.

Un día le pedí al pastor evangélico para que hiciese una campaña allá en mi casa. Me preguntó si yo tenía miedo de mi madre. - Sí, le tengo miedo. No tengas miedo, Dios te va a proteger. Entonces, el pastor vino con veinte evangélicos. Al llegar a casa lo primero que hizo mi madre fue pegarme. Nada más verlos entrar en la casa, el demonio la poseyó, estaba poseída y le salió aquella voz espantosa... Les dijo que ellos no tenían ningún poder, y estuvieron así durante dos horas. Los evangélicos rezando para intentar quitarle el demonio a mi madre, mi madre poseída, y yo agachada llorando en un rincón.

Los evangélicos tardaron cuarenta y ocho días en liberar a mi madre del demonio. Al final lo consiguieron y mi madre también se convirtió a la iglesia

21 Ver Eliade y Couliano (1997).

EMPIRIA. Revista de Metodología de Ciencias Sociales. N.o 24, junio-diciembre, 2012, pp. 93-116. ISSN: $1139-5737$ 
evangélica. Cada vez que veo la película de «El Exorcista» todo aquello me viene a la memoria y se me pone la piel de gallina. Fue igualito que en la película.

Mi madre después cerró el centro de macumba, y a partir de ese día iba diariamente a la iglesia, y comenzó a practicar todas las cosas de los evangélicos. Uno de los que ayudaron en su proceso de liberación era soltero y se casó con mi madre. A minha vida mudóu da auga para o vinho. Ya no tenía que ir corriendo para comprar las galinhas, ni tenía que escribir nombres de personas en las velas, todas aquellas velas amarillas, rojas, negras... Al convertirnos a la Iglesia Evangélica mi vida pasó a ser iglesia y escuela.»

(Cinthia)

Del fragmento anterior puede extraerse esa línea de confrontación directa que se ha ido consolidando en países como Brasil entre las sectas protestantes y las religiones afro-brasileñas. En este sentido, y siguiendo a Jorge de Carvalho, puede decirse que grupos religiosos evangélicos y del movimiento pentecostal han incentivado la práctica de exorcismos de las entidades de origen africano, por lo que de algún modo también se hallan participando del espacio espiritista dominante, aunque sea a través de símbolos de negación (Jorge de Carvalho, 2001: 118). A este complejo religioso en permanente contacto y conflicto Jorge de Carvalho le ha denominado de una forma muy gráfica «querella de los espíritus» ${ }^{22}$. Aunque las entidades invocadas no resultan fáciles de definir, podría decirse, a grandes rasgos, que en el caso de la macumba se procura entablar relación y comercio con los Orixá, las ánimas de los muertos y los Exú, entidades de carácter maléfico, todo lo cual proporciona una relativa atmósfera de magia negra y a que desde el exterior las ceremonias y rituales sean percibidas por los extraños como auténticos escarceos con el diablo.

\section{PROSTITUCIÓN Y PRÁCTICAS MÁGICAS Y DE BRUJERÍA}

A lo largo del trabajo de campo tanto mediante las entrevistas como a través de la observación participante y encuentros informales he podido recabar diferentes indicios y evidencias de una relativa institucionalización de prácticas mágicas y de brujería en el ámbito del trabajo sexual. No todas las referencias pueden circunscribirse a este contexto, pues hay episodios que tienen lugar en el país de origen y que guardan otros significados ${ }^{23}$, pero lo cierto es que determi-

22 Esta dura confrontación ha terminado por llamar la atención de sociólogos, antropólogos y juristas, como bien explica Santos (2011) en relación con la creciente actividad de las iglesias pentecostales establecidas en Brasil, sobre todo de la Igreja Universal do Reino de Deus, que constituye un auténtico fenómeno religioso y social a partir de la década de los setenta.

23 Es un hecho constatado que las prácticas sincréticas derivan de un contexto socio-cultural determinado y que acompañan a los migrantes desde sus países de origen a los de destino, independientemente de la actividad que luego desempeñen estos migrantes. La diferencia estriba, no obstante, en la evolución de estas mismas prácticas en un marco social y simbólico específico, como es en el presente caso la prostitución, máxime teniendo en cuenta el dinamismo y maleabilidad que caracterizan al universo del sincretismo religioso.

EMPIRIA. Revista de Metodología de Ciencias Sociales. N. ' 24, junio-diciembre, 2012, pp. 95-118. ISSN: 1139-5737 
nados hechizos de amor, «trabajos», tratamientos espirituales, consultas a los oráculos, confección de amuletos, uso de velas, rituales de pomba gira y otras prácticas similares encuentran acomodación específica en el entorno de la prostitución.

De especial interés son los rituales de la pomba gira. Aún formando parte de la cosmogonía afro-brasileña en las prácticas sincréticas de umbanda y macumba, el ritual de la pomba gira adquiere una identidad propia. Su origen se encuentra en las entidades denominadas como Exú, que se corresponden con la categoría de los malandros, identificados también con los dioses de carácter demoníaco ${ }^{24}$ y cuyo correspondiente femenino es la pomba gira, diablesa, diosa de la concupiscencia y prostituta ${ }^{25}$. De ahí que exista una estrecha vinculación divina con la prostitución y que muchas trabajadoras sexuales practicantes se identifiquen con ella. Jorge de Carvalho en su artículo «El Misticismo de los espíritus marginales» (2001) recoge varios textos pertenecientes a cantos de pomba gira, algunos de los cuales expresan su contenido espiritual a través de imágenes sexuales explícitas. A modo de ejemplo paso a continuación a transcribir literalmente el siguiente:

\section{Essa puta é minha e ninguém toma quem quiser puta gostosa vai buscar na zona ${ }^{26}$}

Las ceremonias para los Exú son originalmente de una estructura de culto similar que las establecidas para los Orixá. No obstante, en las ofrendas alimenticias se suele incluir aguardiente, tabaco, pimienta y cuando se trata de asuntos eróticos frecuentemente dinero. Así, se observa que algunos de estos rituales han llegado a nuestro país de la mano de la inmigración y se han ido paulatinamente introduciendo en el mercado del sexo, continuando con la esencia sincrética de la transformación y adaptación a nuevos contextos, desvirtuándose en parte y tendiendo tal vez hacia una mercantilización del culto ${ }^{27}$, presente ya por otro lado en la arrolladora industria de las religiones a ambos lados del Atlántico.

Una referencia expresa a las prácticas de pomba gira la encontramos en el relato biográfico de Bruna, donde la protagonista describe un ritual perfectamente adaptado para el trabajo sexual, con el fin de conseguir el éxito económico

24 Para Giobellina y Evangelina se trata de entidades próximas al diablo del catolicismo (1984: 228).

25 «Mujer adúltera, prostituta, arquetipo del amor sexual sin barreras, dueña del cementerio, comanda entidades infernales y es, a la vez, gran protectora y gran vengadora» (Jorge de Carvalho, 2001: 142).

26 [Esa prostituta es mía y nadie me la toma/ el que quiera una prostituta sabrosa/ que la vaya a buscar en el burdel] Traducción de Jorge de Carvalho, 2001: 143.

27 La mercantilización del culto no es un fenómeno exclusivo de las religiones denominadas sincréticas, sino que es más bien una consecuencia del capitalismo globalizado y generalizable por tanto, en mayor o menor medida, a cualquier tipo de confesión religiosa.

EMPIRIA. Revista de Metodología de Ciencias Sociales. N.o 24, junio-diciembre, 2012, pp. 93-116. ISSN: $1139-5737$ 
mediante la intercesión espiritual que proveerá así de un mayor número de clientes.

"Cuando estaba en el club de Ramiro todos los lunes y los viernes limpiaba el club con alcohol y miel. En la barra colocaba Larios y en las mesas whisky, luego cogía un papel y después de echar un poco de whisky sobre la mesa pasaba el papel. Y cogía una pota de agua, echaba 21 clavos (no pueden ser menos ni tampoco más, porque 21 es el número del dinero), canela (si es en trozos como los clavos tienes que poner 21, si no usar una cuchara bien llena) y también dos o tres cucharadas de miel. Hervía todo en la pota, lo dejaba enfriar y con eso limpiaba el suelo. Ese es el modo de que haya mucho trabajo en el club, y de que sólo entren buenos clientes, que no vengan los malos clientes, esos que sólo vienen para tocarte y amasarte y que luego no suben a la habitación. Esto ya lo aprendí en Brasil, allí todo el mundo sabe estas cosas. Son los viejos, las personas mayores, las que te enseñan.

En el club cuando estaba trabajando en el salón también hacía los baños. Aún hoy los hago en el piso. Coloco 21 clavos, 21 trozos de canela, una cucharadita de miel y doce pétalos de rosas amarillas (el color amarillo es el que atrae el dinero) y mezclo todo con colonia en una botella grande de agua. Tienes que dejarlo todo reposar durante tres días. Entonces, te duchas normal, con jabón. Y al terminar te quedas quieta en la bañera y te empapas de amoníaco, te quedas así durante dos o tres minutos y después te vuelves a duchar, quitando todo el amoníaco con jabón. Al terminar, es cuando te vas pasando despacio el baño, despacio, y tienes que dejarlo secar solo, no puedes utilizar una toalla. No puedes secarte, tienes que dejar permanecer toda la energía sobre tu cuerpo. Y cuando vas a trabajar, te colocas el baño en la nuca y en el coño. Así tú vas a trabajar bien.

Hay muchas chicas que usan pomba gira. Es un espíritu malo y también algo peligroso. Tienes que encender una vela roja, no puede ser de otra manera, y poner el nombre del buen cliente o novio a lo largo de toda la vela y de abajo a arriba. Luego, hay que encender la vela en una bandeja y colocar fruta, un cigarro encendido y una copa de champán. Sólo puede ser en viernes, y sólo se debe encender la vela a las seis de la tarde. Tienes que colocar todo en un lugar discreto, para que nadie lo vea, y durante una semana.

Yo no participo de eso, me da un poco de miedo. La única cosa que hago es una simpatía. Coloco un cigarrillo encendido y lo pongo detrás de la puerta en posición de pié. Si después la ceniza se consume toda, sin que caiga el cigarro, quiere decir que voy a trabajar muy bien. Sin embargo, si se cae el cigarrillo es que no voy a ganar ni un euro para comprar pan. Todas esas cosas las aprendí en mi país. Yo creo. Siempre que coloqué el tabaco y se cayó no trabajé nada.

Pero, a mí la pomba gira me da miedo. Yo tengo fe en Dios, creo que es él quien puede ayudarme, y ya está. Aunque, en los clubes hay muchas chicas, la mayoría, que hacen esas cosas. Pero, no sólo las brasileras. Las africanas y las colombianas también lo hacen. Mi tía Isabella también lo hace. Yo no creo que sea cosa buena, porque si lo fuese ella no estaría todavía trabajando en esto después de llevar aquí en España más de diez años y tener sus papeles.»

(Bruna) 
Bruna es una de las muchas brasileñas que evidencian cierta ambigüedad religiosa, que se identifican con el catolicismo y que al mismo tiempo participan en mayor o menor grado de algunas prácticas sincréticas. La descripción del ritual con el tabaco encendido he podido corroborarla en distintos pisos de contactos: en el de Tania, en el de Lorena y Pamela, en el de Romelina, etc. Recuerdo que la primera ocasión en que me encontré con un cigarro encendido incrustado en posición vertical en un limón con un recipiente colocado detrás de la puerta me quedé un tanto sorprendido, aunque intuía que se trataba de algo relacionado con la santería u otros ritos de carácter sincrético. Al preguntarles a mis informantes sobre el objeto en cuestión, ellas me explicaron con toda naturalidad que era «magia para atraer clientes al piso». Esto sucede tanto entre las brasileras como entre las colombianas. Y lo más importante, parece tratarse de una práctica común.

Por otro lado, muchos de estos rituales y ceremonias de carácter sincrético han sabido encontrar su espacio en este mundo del capitalismo globalizado, adaptándose oportunamente a los mecanismos propios de marketing y oferta pública de servicios. Así, en nuestro país cada vez es menos raro el encontrar anuncios en el periódico donde santeros, brujos, sanadores y adivinos de toda guisa ofertan sus servicios. También, cada vez con mayor frecuencia aparecen referencias expresas a rituales de macumba, umbanda y candomblé. Es el resultado del mercado mágico-religioso globalizado, donde compiten santeros, macumberos, espiritistas de todas las tendencias, adivinadores, pais y mâes de santo. A través de su intercesión mágica y espiritual se llevan a cabo gran cantidad de «trabajos»: amarres de amor, sacrificios, confección de amuletos, uso de velas, anulación de fetiches, etc. Muchos de sus clientes son trabajadoras sexuales, aunque no sólo ellas ${ }^{28}$. El mal también se ha globalizado y el nexo causal no conoce de fronteras, por lo que se requiere de soluciones mágicas trans-

28 Hoy en día la oferta de servicios mágico-religiosos no conoce de fronteras y gracias a las nuevas tecnologías como internet ha sabido captar a la clientela autóctona. Así, muchos clientes españoles también recurren a este tipo de prácticas y a los servicios especializados de brujos y pais de santo con el fin de tratar de solucionar problemas, destruir hechizos y realizar «trabajos». En la Comunidad Autónoma de Galicia se observa asimismo un curioso fenómeno de convergencia y de cierta competitividad entre la magia y la brujería tradicional de las meigas y estos recién incorporados profesionales foráneos de lo sobrenatural. A modo de ejemplo voy a citar un caso que conozco personalmente: hace años una joven universitaria comienza a padecer extrañas dolencias; tras un dilatado peregrinaje por varios especialistas médicos sin encontrar un claro diagnóstico y una solución a su enfermedad, la joven y su madre deciden acudir a los servicios de un brujo brasileño quien determina que la causa de su extraño mal está en la magia negra que ha realizado una meiga lucense por encargo de unos familiares de la propia joven que desean su sufrimiento, por lo que para «deshacer el trabajo» el brujo solicita que se lleven a cabo una serie de acciones encaminadas a este fin. La relación del brujo brasileño con la familia gallega se prolonga ya varios años y la joven continúa gravemente enferma. La fe de esta familia en los poderes (benefactores) del brujo y (maléfi$\cos$ ) de la meiga resultan ciertamente conmovedores. El contacto con el brujo brasileño se hizo por internet pues en este caso los servicios se ofertan a través de la red. Pero, en otros casos brujos y sanadores que se han establecido en nuestro país ofrecen sus servicios especializados a través de sencillos anuncios en el periódico local.

EMPIRIA. Revista de Metodología de Ciencias Sociales. N. ${ }^{2}$ 4, junio-diciembre, 2012, pp. 93-116. ISSN: $1139-5737$ 
oceánicas. La persona que «cruza el trabajo» puede hallarse en Brasil y la trabajadora sexual brasileña que se ocupa en un piso en Galicia puede sufrir las consecuencias. El origen de la desdicha también puede ser cercano y tratarse de una compañera de trabajo. Pero, resulta indispensable tener fe. Hay que creer y tener fe, sino no hay resultados como afirma Ana Paula, la joven de Manâos que acude al pai de santo con el fin de recuperar el estado de bonanza económica y el éxito en el trabajo ${ }^{29}$.

«Una compañera del club me dio el número de teléfono de un pai de santo. Él es un pai de santo de Bahía, pero ahora está en Sâo Paulo. Lo llamé. Conversó conmigo. Me ha dicho que no debo estar deprimida, que tengo que levantar cabeza, que tengo que luchar para que me salgan mis papeles... Me preguntó cosas y jugó las conchas. Luego me dijo que mi problema era por causa de una chica morena, alta, con la que yo había discutido. Ahí me di cuenta de que había sido la dominicana. Ella fue la única persona con la que he peleado. Fue por causa de un cliente en «El Edén». El pai de santo me explicó que por ese motivo yo he estado tanto tiempo parada, que si no hubiese sido por eso yo ya habría conseguido mis objetivos hacía tiempo. Estuvimos hablando durante una hora. Luego, él me dio su número de cuenta y a la semana siguiente le pagué cuarenta euros (unos ciento veinte reales). Él confía en la gente, y claro, él también tiene mi nombre y mi fecha de nacimiento...

Hablé varias veces con él. Me dice que no debo confiar en las compañeras del club. No debo aceptar cosas que me ofrezcan para comer ni así. Pueden tratar de hacerme daño. Sobre todo tengo que tener cuidado con las colombianas, que son las peores. Las dominicanas y las brasileras también, pero más las colombianas. Tengo que tener precaución de las chicas que me miran mal. Ellas intentan causarte daño porque sienten envidia y tratan de dejarte parada.

Debes tener fe para que resulte. En Brasil yo ya fui a pais de santo y también a ceremonias de umbanda, pero no me dio resultado. Tienes que creer y tener fe. Yo no había participado mucho en estas cosas. Antes de viajar a España consulté a una echadora de cartas, que me dijo que yo iba a hacer un viaje a un lugar muy lejano y que iba a conseguir todo lo que yo quería, pero tendría que afrontar también muchas dificultades, pasar muchas barreras... En aquella época yo no sabía todavía que iba a viajar a España... Fue cuando me marché para Venezuela. Pero, Venezuela no es un lugar muy lejano.

Aqui en Lugo fui también a una echadora de cartas colombiana. Fue antes de llamar al pai de santo. Me dijo que yo estaba muy triste y apagada, muy pensativa. Le conté que era porque no estaba trabajando. Me explicó que debería tomar un baño de manzana. Y me dijo que había muchos hombres en mi vida, y que iba a conocer a un hombre muy rico, muy celoso y que, aunque estaba comprometido, él me iba a ayudar. Pero, para conocer a ese hombre yo

29 Hechos como el aquí descrito nos aproximan a esa función psicológica y social de la magia tal como explica Malinowski cuando afirma que las prácticas mágicas se originan a partir de respuestas emocionales ante situaciones de frustración (Morris, 1995: 187).

EMPIRIA. Revista de Metodología de Ciencias Sociales. N. ${ }^{24}$, junio-diciembre, 2012, pp. 95-118. ISSN: $1139-5737$ 
tengo que viajar. Para conseguir todo lo que yo quiero debo de salir de Lugo. Tengo que marcharme y hacer alguna plaza por ahí. Aquí ya estoy muy vista y me siento cansada. La misma gente, las mismas caras...

El pai de santo ayuda a muchas personas famosas, artistas, etc. Toda la gente que tiene éxito lo consigue a través de este tipo de trabajos. La Xuxa ${ }^{30}$, todos. No hay uno solo que no se mezcle con estas cosas. Yo no tuve suerte hasta ahora porque nunca quise participar de estos trabajos. Y ahora es cuando mi vida comienza a mejorar. Ahora estoy empezando a trabajar. Mi suerte ha comenzado a iluminar mi camino. Estoy haciendo mis siete baños para quitar todos los males, para purificarme. Tengo que hacer los baños los lunes, los miércoles y los viernes. Después, él me hace el trabajo. No sé aún cómo es exactamente. Colocan una mesa como un banquete, con sacrificios de animales para ofrecer a los espíritus y así ellos puedan ayudarme. Yo le pago a plazos. Le envío una parte del dinero. Sólo le envío el resto del dinero cuando compruebo que el trabajo está dando resultado.

Para conseguir el éxito es necesario hacer estos trabajos. Aquí hay mucha gente mala. Muchas chicas que tienen envidia, que te miran con ojos grandes. El pai de santo está muy ocupado. Tienes que concertar una cita para que pueda atenderte. Cuando consiga mis objetivos, pediré también un trabajo para ayudar a mi familia...»

(Ana Paula)

Al contrario que Ana Paula, Cinthia manifiesta escepticismo y desconfianza ante este tipo de rituales, tal vez porque los conoce muy de cerca desde su infancia, aunque al mismo tiempo evidencia cierta ambigüedad religiosa y termina acudiendo a solicitar los servicios profesionales/espirituales de un babalao. Diversos estudios avalan la idea de que en algunos países latinoamericanos como Brasil una mayoría de la población que se declara católica participa asimismo en mayor o menor medida de rituales religiosos de carácter sincréti$\mathrm{co}^{31}$. Aunque esto último pueda parecer contradictorio, hay que pensar que los cultos de origen animista manifiestan una adherencia de creyentes relativamente abierta y nunca excluyente. Por otra parte, la comercialización del culto, el turismo de masas, los propios movimientos migratorios y el avance tecnológico han terminado por desvirtuar en cierta forma la auténtica experiencia espiritual, resultando a veces muy difícil el poder «distinguir el oro del trigo».

«Tenían allí un veado macumbero ${ }^{32}$ que el primer día que llegué me pidió que me quitase toda la ropa y me colocase una toalla blanca alrededor de la

30 Artista y cantante famosa en Brasil.

31 Una encuesta realizada en 1992 por el Instituto de Estudios de la Religión (ISER) de Río de Janeiro ofrece como resultado que el $64 \%$ de los católicos en Brasil se relaciona en alguna medida con religiones afro-brasileñas y corrientes espiritistas (Carneiro y Soares en Jorge de Carvalho, 2001)

32 En su estudio sobre la santería Fernández Cano menciona el hecho de que un número muy significativo de santeros son homosexuales (2005). Por otra parte, existen interesantes estudios etnográficos que analizan la relación que se establece entre las travestis y el candomblé (Don Kulick, 
cintura. Entonces, me llevó al río que había cerca del club y me quitó la toalla, colocándome de espaldas al río, y con un huevo de galinha me tocaba todo el cuerpo y hacía cruces. Me decía que me estaba despojando de todo el mal que llevaba conmigo y que de esa forma también iba a ganar mucho dinero. También me pasaba pipoca por toda mi piel. Todo eso duró unos veinte minutos y recuerdo que hacía un frío do caralho.

Después, regresamos al club. Me pidió que me pusiese una ropa de color rojo y que así iba a trabajar de puta madre. Aquella noche no hice ni un puto pase. Al día siguiente aquel veado me preguntó: — ¿Qué tal el trabajo, Cinthia? - Mal, ni un puto pase, y debiendo cuarenta euros de casa. -Tranquila, vamos a hacer otra cosa, ya verás. Entonces, le contesté que ya no quería más ceremonias de esas, que no me interesaba. Él sólo quería mi dinero, cobraba treinta euros por consulta. Le dije que no necesitaba macumba ninguna, que mi macumba era abrir las piernas.

(...) La macumba sólo servía para darle dinero a los dueños a través de las copas que tomaban los clientes. Todos los días estaba lleno. Nunca vi un putero tan lleno de hombres.»

(Cinthia)

El macumbero del que habla Cinthia es un buen ejemplo de profesionalización aplicada a la industria del sexo. De forma similar a otros ofertantes de servicios como vendedores de ropa, joyas y preservativos, el brujo macumbero brinda sus consejos espirituales y prepara «trabajos» para las prostitutas. No obstante, no he tenido oportunidad de conocer «in situ» una adscripción espiritista tan específica. Lo que sí puede comprobarse a través de anuncios en el periódico es la proliferación en los últimos años de la oferta de servicios mágicos con expresa alusión a rituales afro-brasileros (macumba, umbanda y candomblé) y afro-caribeños (santería y vudú). Así, por ejemplo, en «El Progreso» de Lugo se mantiene constante una media de una docena de anuncios diarios en la sección de astrología y videntes. Paso a continuación a reproducir algunos de estos:

«CAXAMBÚ TAROT BRASILEÑO, recupera tu pareja, abre tus caminos, magias, videncia. Tel.:

(El Progreso, 7 de enero de 2003)

«SANTERA YAZMIN ALTA MAGIA. Sin imposibles. Abona al obtener resultado. $100 \%$ efectivo. Tel.:

(El Progreso, 5 de mayo de 2005)

«BABALAWO, EDUARDO DE XANGÓ, mal de ojo, amarres, tarot, caracolas, endulzamientos. Citas. Tel.:

(El Progreso, 5 de mayo de 2005)

1998; Larissa Pelúcio, 2009). Así, esta última autora afirma que el hecho de «ser travesti» en Brasil no puede separarse de rasgos culturales como el candomblé, las concepciones de sexo y género de las clases populares o «la noche» como espacio simbólico. De los datos etnográficos recogidos, Pelúcio afirma asimismo la existencia de esa relación travesti/candomblé, que se evidencia en algunas expresiones como bajubá o pajubá características de la jerga de las travestis brasileñas, así como en las representaciones de género que remiten a la cosmología del sincretismo religioso.

EMPIRIA. Revista de Metodología de Ciencias Sociales. N. ${ }^{24}$, junio-diciembre, 2012, pp. 95-118. ISSN: $1139-5737$ 
«VIDENTE AFRICANO especialista temas espirituales, amor, recuperación pareja inmediata. Tel.:

(El Progreso, 5 de diciembre de 2008)

De la información recabada ${ }^{33}$, puedo indicar que el vidente africano y la santera cubana son los que han mantenido su actividad durante más tiempo en la ciudad. El primero es un inmigrante nigeriano que ofrece consulta previa cita y que practica diversos rituales que guardan posible relación con la religión yoru$\mathrm{ba}^{34}$. Varias de mis informantes han acudido a su consulta y aseguran que practica magia negra ${ }^{35}$. En cuanto a la mujer cubana ofrece servicios de adivinación y encantamiento que trata de integrar en el universo ritual de la santería.

Pero, hoy día internet es una vía también muy utilizada por diferentes mercaderes de las religiones. De esta forma, resulta muy sencillo entablar contacto con un pai de santo brasileño que se anuncia y oferta sus múltiples servicios mediante la red. Para el profano, sin embargo, es una tarea muy difícil el poder distinguir las actividades propias de un auténtico babalao umbandista o un santero de los pseudo-rituales que suelen adoptar aquellos que se identifican con las religiones animistas y el espiritismo con el único fin de obtener un beneficio económico, esto es, los farsantes que viven al margen de la brujería y se lucran con ella, sin creer en ella (Henríquez, 1970).

Por otro lado, existe la práctica cotidiana e individualizada de determinados conjuros y hechizos en lo que podemos identificar como el universo mágico y/o de brujería. Siguiendo a Kottak (2000) magia son las técnicas sobrenaturales orientadas a alcanzar propósitos específicos, incluyendo conjuros, fórmulas y encantamientos utilizados con deidades o con fuerzas impersonales. Para Henríquez la magia es hermana menor de la religión, separándose de ésta principalmente por sus procedimientos. Desde la elaboración y uso de algunos fetiches y amuletos hasta los encantamientos y amarres de amor. Son, desde luego, prácticas frecuentes entre las trabajadoras sexuales brasileñas y colombianas pues su ámbito de aplicación es amplio y diverso, sirviendo estos «trabajos» tanto para fomentar la llegada de clientes y el aumento de las ganancias económicas como para adscribir a los mejores clientes y enamorar a determinados hombres. Hay que señalar, sin embargo, que a pesar de que la mayoría de estas prácticas tienen su origen en el universo religioso sincrético afro-americano, la existencia de prácticas mágicas con fines similares es prácticamente universal, existiendo asimismo prece-

33 Testimonio de algunas trabajadoras sexuales que acudieron a las consultas así como información recogida en la comisaría de policía de Lugo.

34 Religión practicada en Nigeria y países limítrofes, es posiblemente la religión africana que cuenta con un mayor número de creyentes (Eliade y Couliano, 1997: 33). Un sencillo vistazo sobre la cosmogonía yoruba es suficiente para evidenciar la enorme influencia que ha desempeñado esta religión en la construcción del sincretismo en América, encontrándose aquí el origen de divinidades como los Orisas, entre los cuales hallamos también a los espíritus Exú, entidades tramposas que requieren ofrendas y sacrificios. 2008: 51 .

35 Para una descripción de la ceremonia del juju (vudú) ver Kastner en Solana y Acién eds., 
dentes de la utilización de conjuros y recetas mágicas de carácter erótico en el ámbito europeo y español como así se demuestra a través de la publicación de distintas obras: El libro de San Cipriano (1810), La ciencia del amor (1923) o Magia sexual (años veinte) del editor barcelonés Rosendo Pons ${ }^{36}$. No obstante, la práctica cotidiana de la magia y de la brujería se corresponde más bien con un sistema de tradición oral que no con el uso y mediación de grimorio ${ }^{37}$ alguno. En este sentido, una práctica también muy arraigada en el ámbito de la prostitución es la conocida como «cruzar el trabajo» que consiste en que alguien (normalmente una compañera del oficio) recurre a la brujería con el fin de que mediante algún tipo de sortilegio maléfico se infiera sobre la víctima (una trabajadora sexual) un daño que se traduce, por lo general, en la pérdida de clientes y el fracaso económico. Estaríamos, pues, ya en el terreno de la magia negra ${ }^{38}$.

«En los pisos trabajando en esto también hay chicas que saben cruzar el trabajo. Te hacen brujería y entonces estás parada, no te haces un solo pase. Karen cree mucho en todas estas cosas. Antes de la discusión y de que ella se marchase para el piso de mi hermana, yo ya la había notado muy rara. A mí me parecía que tenía problemas con el trago o la droga. Un día fui a golpearle a la puerta y entré en la habitación, y olía horrible, como muy raro. $Y$ Karen no quería que yo entrase en la habitación. Y otro día, poco antes de que ocurriera todo ${ }^{39}$, cuando hice aseo encontré varios papeles de aluminio quemados y que desprendían un olor muy raro. Se me hizo extraño, pero no le di más importancia al asunto.»

(Tania)

Las prácticas de brujería se hallan estrechamente vinculadas a los acontecimientos mundanos. A causa de los celos, la envidia o cualquier tipo de conflicto inter-personal, alguien puede recurrir a la magia negra y en un entorno tan competitivo como es el de la prostitución la mediación de la brujería no es un fenómeno raro. Muchas veces he escuchado de boca de las trabajadoras sexuales que el principal enemigo que ellas tienen son las propias compañeras. Así, la magia y la brujería constituyen un sutil sustitutivo de la violencia explícita. Tanto es así que las acusaciones de practicar la brujería que se achacan entre sí se han

36 Félix Castro Vicente (2009) realizó un estudio titulado «Breve reseña de algunos libros de magia erótica españoles de inicios del siglo $X X »$ donde lleva a cabo una interesante labor de aproximación a las diferentes publicaciones de magia amorosa y sexual en aquella época en nuestro país. El estudio es inédito y se presentó como trabajo de investigación para la asignatura Antropología de la Sexualidad. Dep. Sociología I. Facultad de CC. Políticas y Sociología. UNED.

37 Libro de magia.

38 Suele distinguirse entre magia homeopática o imitativa, que es la que produce el efecto buscado mediante la imitación, y magia contagiosa o contaminante, que es la que se sirve de cualquier objeto que haya estado en contacto con la persona afectada (Kottak, 2000: 84). Vengo a utilizar aquí la expresión «magia negra» en el sentido más corriente de magia practicada con el fin de causar daño o perjuicio a otro.

39 La narradora se refiere a una grave discusión que mantuvieron ella y Karen en el piso y que terminó con la definitiva separación y enemistad entre ambas.

EMPIRIA. Revista de Metodología de Ciencias Sociales. N. ${ }^{24}$, junio-diciembre, 2012, pp. 95-118. ISSN: $1139-5737$ 
vuelto tan comunes como las referidas a trabajar sin preservativo en una estrategia global de tratar de desacreditar al otro. Un buen ejemplo lo encontramos en la evolución de la relación que tuvo lugar entre Tania y Karen. Ambas intentaron convencerme, a su manera, de que «la otra» era una bruja.

«(...) Tania es una mala persona. A mí me tenía jodida. Sabe, ella es una bruja. Sí, no se ría, ella hace cosas de brujería. Cualquier día le hace una a usted, si es que no se la ha hecho ya. Mire, recuerdo, por ejemplo, lo que pasó cuando lo de Lorena. Ella me dijo un día que la iba a sacar del piso. Y cogió un día y me dijo: -Venga, vámonos al cementerio. Fuimos con un amigo que nos llevó allá, al cementerio, al de Lugo no, al de Rozas, allí cerca del club. Entonces, fuimos y cuando llegamos al cementerio ella nos dijo: Ustedes esperan acá. Y ella entró y estuvo allí sola en el cementerio haciendo no sé qué cosas. Estuvo como una media hora y luego se vino. Y fue cuando me dijo: - He sacado a Lorena del piso. Y así fue, que al día siguiente Lorena se marchó del piso. Ya sabe usted, que hubo todos aquellos problemas por Toño y eso. Sí, Tania sabe de esas maldades, ella es bruja.

(...) Los martes y los viernes es cuando trabajan esas cosas. A mí me dieron las crisis de madrugada. Yo hablé incluso con don Carlos para que me hiciera unos baños para la suerte. Los baños son hierbas así naturales que le mandan a uno para hacerse. Pero, don Carlos es muy amigo de Tania. Él hace «recorridos». Los «recorridos» son que le trabajan a uno con el espíritu, con los nombres y los apellidos, cuando está dormido. El fin puede ser distinto, dependiendo de si se quiere o se odia a la persona. Don Carlos hace el trabajo que uno quiere que le haga, sea para un bien o para un mal. Él lo hace.»

(Karen)

Al brujo don Carlos también hace mención Romelina, hermana de Tania, con quien Karen se marcharía finalmente a vivir y a trabajar en su piso, aliándose con ella y transformándose así nuevamente el tándem de amor-odio que vincula a los personajes.

"Yo me enteré por mi mamá de que mi hermana Tania le había encargado un trabajo a don Carlos, que es un viejo que hace cosas de brujería. Mi hermana le encargó para que yo y Karen saliésemos perjudicadas. Yo he estado muy nerviosa, pero Karen estuvo muy mal, le dio como una crisis la semana pasada, que la tuvimos que llevar al hospital y todo.

Don Carlos vive allá enfrente de la casa de mi mamá. Yo no lo conozco personalmente. No me interesa ese tipo de gente. Pero, sé que él hace esas cosas. Mi hermana le llama y le hace encargos para conseguir hacernos daño. Ya cuando Karen estaba del otro bando, ya me entiendes..., que ella vivía con mi hermana, le escuchó un día comentar que Lorena se iba a marchar del piso en quince días. Y así ocurrió. Y en otra ocasión, Karen le acompañó a mi hermana a un cementerio, porque le dijo que iba a hacer unas cosas. Pero, Tania entró sola y Karen se quedó en la puerta, así que no pudo ver cuáles fueron las maniobras.

Mi hermana ya mantenía una guerra con la suegra, en Villa Margarita. $Y$ yo le vi coger los retratos y colocarlos del revés, y también ponerles unos al- 
fileres. Bueno, que la suegra también le colocaba a mi hermana cosas. Era una guerra terrible entre las dos.»

(Romelina)

La importancia de los ritos y prácticas sincréticas también se manifiesta a través de los significados de que hacen gala las trabajadoras sexuales durante la interpretación de los acontecimientos mundanos, integrando en su discurso hechos y fenómenos que tuvieron lugar en sus países de origen. Es así como el universo espiritual forma parte de su propio acervo cultural. A ello hay que añadir, la flexibilidad intrínseca del sincretismo que facilita, por otro lado, la incorporación de nuevos elementos ${ }^{40}$. Mujeres como Tania, Amanda, Ana Paula o Bárbara acudieron alguna vez ya en su país a consultas de babalaos o brujas con el fin de hacer o deshacer entuertos. La religiosa y espiritual es, en síntesis, una herencia cultural que también se traslada al país de destino a través de la migración.

«Cuando yo tenía diecinueve años una chica me hizo brujería. A ella le gustaba el padre de mi hija. Cogió una piel de ternera y metió dentro un montón de porquería.

Como yo tenía mucho dolor de cabeza y los médicos no sabían qué me ocurría, mi hermana, que es muy creyente, me llevó a un curandero. Así fue cómo lo descubrimos. Aquel hombre nos indicó el lugar exacto donde estaba la piel de ternera. Y tenía que deshacer el trabajo. Entonces, me tocó la cabeza y de repente sentí un alivio muy grande. También recitó unas oraciones. Él curaba con agua y piedra. El agua era la que le mostraba las cosas. Podía ver lo que pasaba a través de un vaso de agua.

La piel estaba cosida y colgada en un árbol con un gancho. Dentro había sangre y un montón de inmundicia, también había varias cosas mías, hasta unas calçinhas. Aquella mujer pretendía que yo me quedase ciega para así ella poder quedarse con Fabio. Fue el curandero quien descolgó aquello. Brujería pesada. El mismo curandero llamó a la chica y ella le confesó todo. Si no confesaba, el trabajo podía volverse contra ella.»

(Amanda)

Problemas amorosos fueron los que también llevaron a Bárbara a acudir a una hechicera. La diferencia estriba básicamente en el resultado. Mientras Amanda consiguió un resultado exitoso ya que el curandero logró deshacer el trabajo de magia negra que habían hecho sobre ella, Bárbara, por el contrario, fracasó en su intento de recuperar mediante prácticas de brujería a su enamorado, por lo que se sintió estafada ${ }^{41}$.

40 En este sentido, señalar que el espiritismo animista latinoamericano engarza bastante bien con la tradición europea de contacto con los muertos y el más allá, tradición muy viva en regiones como Galicia donde permanecen todavía creencias como las de las meigas y de la santa compaña.

41 De esta forma, la contratación de servicios profesionales de brujos, magos y curanderos parece ser una excepción a la del resto de servicios profesionales en el actual sistema de mercado pues no se rige por una «lex artis» en atención a los recursos y medios debidamente utilizados, sino más bien específicamente por el resultado obtenido. De ahí que al considerar la magia y la brujería como prácticas infalibles cualquier error en el resultado será interpretado fácilmente como una negligencia del actor y/o un engaño.

EMPIRIA. Revista de Metodología de Ciencias Sociales. N. ${ }^{24}$, junio-diciembre, 2012, pp. 95-118. ISSN: $1139-5737$ 
"Un día fui a una bruja en Curitiba, para que me hiciese una magia a ver si Paco me cogía el teléfono. Tuve que ir a una cachoeira en medio de la selva para poner velas. Me gasté una pasta con aquella bruja... Era una estafadora. Siempre me ponía excusas. Que si en Azores había otra persona que le estaba haciendo magia a él..., y yo me lo creía todo, hostia, y cómo. Tenía que comprar velas, que comprar pólvora, que comprar la puta que la parió. Me encontraba muy débil psicológicamente y ella se aprovechó de mí. Pero, al final peleé con esa bruja y le dije que me estaba engañando. Desistí.»

(Bárbara Love)

En uno de los pisos de contactos pude comprobar empíricamente la práctica de magia de carácter sexual. Se trata de introducir semen del ser pretendido o amado en un tarro en el que hay de base un contenido con algunos productos naturales como miel por ejemplo. Luego, se guarda el tarro con el contenido en la nevera y manteniéndolo así durante un tiempo se consigue el amarre. La acción en este caso la había llevado a cabo Lorena, una compañera del piso de Tania, que estaba enamorada de Toño, un cliente/amigo gran frecuentador de los pisos. Ella me mostró el tarro en cuestión que conservaba guardado en el frigorífico. Sé que Lorena y Toño salieron juntos durante algún tiempo, aunque Toño alternaba sus atenciones también con otras mujeres por lo que mantengo mis reservas acerca de la efectividad de la fórmula. La propia Tania hace una descripción de este amarre, así como otras consideraciones sobre las prácticas de magia y de brujería en los pisos.

«Dicen que en estos pisos donde trabajamos se oyen cosas. Pasan cosas raras. Dicen que el diablo permanece en estos pisos. Dicen que a determinadas mujeres se les presenta el diablo al menos una vez al año, sí, a las que trabajamos en este oficio (...) Aquí en los pisos de Lugo hay muchas chicas que hacen brujería. Por ejemplo, se pone esperma del hombre dentro de un tarrito de cristal con miel, y se coloca el nombre y la fecha de nacimiento. Esto se hace para que el hombre permanezca atado a la mujer. Y para que cuando vaya a tener relaciones con otras mujeres no consiga tener el orgasmo. Así sólo lo conseguirá con ella. En el piso de Perpetuo Socorro teníamos un tarrito de Toño y otro de Eduardo.»

(Tania)

La línea que separa la práctica mágica y el imaginario colectivo mitológico popular es también una línea tenue. El denominador común es que el informante está haciendo una clara referencia al mundo de lo sobrenatural ${ }^{42}$. De ahí, que durante las entrevistas cuando se abordan estos temas la persona entrevistada puede construir un discurso relativamente confuso, donde se mezclan elementos propios de la brujería con otros que se derivan más bien de la mitología y leyendas populares. Asimismo, el particular significado que el sujeto otorga a este

42 Para un análisis sociológico de la característica de lo sobrenatural en la religión ver Las formas elementales de la vida religiosa (1993: 64-71) de Durkheim.

EMPIRIA. Revista de Metodología de Ciencias Sociales. N. ' 24, junio-diciembre, 2012, pp. 93-116. ISSN: $1139-5737$ 
tipo de fenómenos puede remitir de nuevo a la magia, a creencias religiosas o incluso a prácticas supersticiosas en un afán personal de ordenar y entender el mundo que le rodea.

\section{CONCLUSIONES}

La importancia de las prácticas mágico-religiosas en un contexto de prostitución se halla claramente influenciada por el marco cultural de los sujetos migrantes, pero no se reduce a esta circunstancia sino que adquiere relevancia precisamente al mostrar su dimensión más específica y capacidad de adaptación al propio funcionamiento y dinamismo de la industria del sexo. Los datos aquí recogidos son tan sólo un esbozo. Una investigación seria y profunda sobre estas prácticas religiosas y su recepción en los países de destino a través de los flujos migratorios requiere de una inmersión en el campo más especializada. «La globalización supone un nuevo escenario en el cual las reflexiones en torno a los fenómenos de sincretismo vuelven a cobrar valor» (Malgesini y Giménez, 2000: 391). Con este artículo tan sólo pretendo expresar aquí el interés que suscita un objeto de estudio apasionante y prácticamente sin explorar en nuestro país, sobre todo si lo colocamos en relación, contextualizándolo debidamente, con el trabajo sexual.

De igual forma, un análisis exhaustivo de la prostitución puede ser también una excelente oportunidad para encarar con interés el estudio de todo este conjunto de creencias mágico-religiosas, prestando especial atención a aquellas prácticas y rituales que guardan relación directa con el trabajo sexual (para conseguir el éxito económico atrayendo a la clientela, para eliminar la competencia, para «fidelizar» o enamorar a algunos clientes, etc) y que se hallan indefectiblemente instaladas en nuestro país. Un abordaje que deberá de acometerse preferentemente mediante el método etnográfico y siempre desde una perspectiva socio-antropológica, sin hacer concesiones al etnocentrismo o a ideas preconcebidas que puedan perturbar el trabajo de investigación ${ }^{43}$. Etnocentrismo desde el cual nuestra siempre biempensante y redentora sociedad occidental repudia fácilmente las prácticas sincréticas a medida que construye los pilares sagrados bajo los cuales la industria del rescate ${ }^{44}$ ha terminado por edificar su propia catedral.

43 De hecho, las únicas referencias a prácticas sincréticas que suelen hacerse desde diferentes estudios e investigaciones sobre prostitución son profundamente parciales y estigmatizadoras como es el caso de los rituales de vudú que supuestamente utilizan las organizaciones y redes de tráfico de mujeres provenientes de países africanos como Nigeria con el fin de explotar sexual y económicamente a jóvenes migrantes.

44 Expresión acuñada por Agustín (2009) y con la que se hace referencia a todo el entramado de asociaciones, poderes públicos e instituciones que desde una postura ideológica abolicionista de la prostitución y a través de la práctica indiscriminada de la victimización de las trabajadoras sexuales, oculta la realidad de un negocio muy lucrativo en términos monetarios y de prestigio profesional.

EMPIRIA. Revista de Metodología de Ciencias Sociales. N. ${ }^{24}$, junio-diciembre, 2012, pp. 95-118. ISSN: 1139-5737 


\section{BIBLIOGRAFÍA}

AGUSTÍN, L. (2009): Sexo y marginalidad. Emigración, mercado de trabajo e industria del rescate, Madrid, Editorial Popular.

BULlOUGH, B \& BULlOUGH, V. (1964): The History of Prostitution, New York, University Books.

- (1996): «Female Prostitution: Current Research and Changing Interpretations». Annual Review of Sex Research, Vol. VII: 158-180.

CARMONA, S. (2007): Ellas salen. Nosotras salimos, Barcelona, Icaria.

CASTRO VICENTE, F. (inédito): Breve reseña de algunos libros de magia erótica españoles de inicios del siglo XX. Trabajo presentado en 2009 para la asignatura de Antropología de la Sexualidad. Dep. Sociología I, Facultad de CC. Políticas y Sociología, Madrid, UNED.

DE PAULA, R. (2000): Hablan las Putas, Barcelona, Ed. Virus.

DURKHEIM, E. (1993): Las formas elementales de la vida religiosa, Madrid, Alianza Editorial.

ELIADE, M. y COULIANO, I. (1997): Diccionario de las religiones, Barcelona, Círculo de Lectores.

FERNÁNDEZ CANO, J. (2005): «Entre Oyá y santa Teresa. El controvertido asunto del sincretismo en la santería». Gazeta de Antropología, no 21, 2005.

FOUCAULT, M. (2005): Historia de la sexualidad. 1. La voluntad de saber, Madrid, Siglo XXI.

GIOBELLINA, F. y EVANGELINA, E. (1984): «Umbanda. Notas sobre un fenómeno religioso brasileño». Revista Española de Antropología Americana, vol. XIV, Ed. Universidad Complutense de Madrid: 227-242.

GIOBELLINA, F. (2005): «A propósito de la jurema. Reflexiones sobre el campo religioso brasileño». Revista de Antropologia, vol. 48, n² 2, Sâo Paulo, USP: 443-460.

HENRÍQUEZ, E. (1970): Crímenes de la brujería, Buenos Aires, Depalma.

JORGE DE CARVALHO, J. (2001): «El misticismo de los espíritus marginales». Revista Colombiana de Antropología, vol. 37: 112-150.

JULIANO, D. (2002): La prostitución: el espejo oscuro, Barcelona, Icaria.

-(2004): Excluidas y marginadas, Madrid, Cátedra.

KASTNER, K. (2008): «Cuerpo, corporeidad y migración. Nigerianas a ambos lados del Estrecho» en Los retos de la prostitución. Estigmatización, derechos y respeto (Solana y Acién eds.: 45-57), Granada, Comares.

KOTTAK, C. (1997): Antropología Cultural. Espejo para la humanidad, Madrid, Ed. McGrawHill.

KULICK, D. (1998): Travesti: Sex, Gender and Culture among Brazilian Transgendered Prostitutes, Chicago, University of Chicago Press.

LÓPEZ RIOPEDRE, J. (2004): Mara y sus amigas. Investigación sobre la prostitución en Galicia, Lugo, Manuscritos.

-(2010): Inmigración colombiana y brasileña y prostitución femenina en la ciudad de Lugo: Historias de vida de mujeres que ejercen la prostitución en pisos de contactos. Tesis doctoral. Dep. Sociología I, Facultad de CC. Políticas y Sociología, Madrid, UNED.

-(2011): «La criminalización de la industria del sexo, una apuesta políticamente correcta». Gazeta de Antropología, nº 27/2.

EMPIRIA. Revista de Metodología de Ciencias Sociales. N. . 24, junio-diciembre, 2012, pp. 93-116. ISSN: $1139-5737$ 
MALGESINI, G. y GIMÉNEZ, C. (2000): Guía de conceptos sobre migraciones, racismo e interculturalidad, Madrid, La Catarata.

MORRIS, B. (1995): Introducción al estudio antropológico de la religión, Barcelona, Paidós.

NANDA, S. (2003): «Hijra y Sâdhin. Ni hombre ni mujer en la India» en Antropología de la sexualidad y diversidad cultural (Nieto ed.: 261-274), Madrid, Talasa.

NIETO, J.A. (2011): Sociodiversidad y sexualidad, Madrid, Talasa.

OSBORNE, R. (1991): Las prostitutas: una voz propia, Barcelona, Icaria.

- (2002): La construcción sexual de la realidad, Madrid, Cátedra.

-(2004): Trabajador@s del sexo.Derechos, migraciones y tráfico en el siglo XXI, Barcelona, Bellaterra.

PARKER, C. (2000): «Desoccidentalizar. Desafío estratégico y perspectiva para las Ciencias Sociales de la Religión en América Latina». Newsletter de la Asociación de Cientistas Sociales de la Religión en el Mercosur, $\mathrm{n}^{\circ}$ 10, 5-7.

PHETERSON, G. (1989): Nosotras las putas, Madrid, Talasa.

-(2000): El prisma de la prostitución, Madrid, Talasa.

PELÚCIO, L. (2009): «Sin papeles, pero con glamur. Migración de travestis brasileñas a España». Vibrant, vol. 6, nº 1: 170-197.

SANTOS, M. (2011): «Pluralismo, liberdade religiosa e proselitismo: o Estado Brasileiro e a Guerra Santa entre os Neopentecostais e as religiôes afro-brasileiras». XI Congresso Luso Afro Brasileiro de Ciências Sociais, Salvador, agosto 2011. Universidade Federal da Bahia (UFBA).

SOLANA, J.L. y LÓPEZ RIOPEDRE, J. (2012): Trabajando en la prostitución. Doce relatos de vida, Granada, Comares.

WEITZER, R. (2006): «Moral Crusade Against Prostitution». Society, march/april 2006: 33-38. 
